\title{
Usefulness of near infrared reflectance (NIR) spectroscopy and chemometrics to discriminate between fishmeal, meat meal and soya meal samples
}

\author{
Daniel Cozzolino1, Ernesto Restaino², Alejandro La Manna², \\ Enrique Fernandez ${ }^{2}$, and Alberto Fassio ${ }^{2}$ \\ ${ }^{1}$ The Australian Wine Research Institute. Waite Road, Glen Osmond, PO Box 197, Adelaide, Australia, 5064 \\ ${ }^{2}$ Instituto Nacional de Investigación Agropecuaria, Estación Experimental INIA La Estanzuela. \\ Ruta 50, km 12, Colonia, Uruguay.
}

\begin{abstract}
D. Cozzolino, E. Restaino, A. La Manna, E. Fernandez, and A. Fassio. 2009. Usefulness of near infrared reflectance (NIR) spectroscopy and chemometrics to discriminate between fishmeal, meat meal and soya meal samples. Cien. Inv. Agr. 36(2):209-214. Near infrared reflectance (NIR) spectroscopy was used in combination with chemometrics to discriminate between fishmeal, meat meal and soya meal samples. Samples were obtained from commercial feed mills and scanned in the NIR region $(1100-2500 \mathrm{~nm})$ in a monochromator instrument in reflectance mode. Principal component analysis (PCA) and linear discriminant analysis were used to classify samples based on their NIR spectra. Full cross-validation was used in the development of classification models. Partial least squares-discriminant analysis (PLS-DA) correctly classified $85.7 \%$ of the fishmeal samples and $100 \%$ of the meat meal and soya meal samples. These results demonstrate the usefulness of NIR spectra combined with chemometrics as an objective and rapid method to classify fishmeal, meat meal and soya meal samples. NIR spectroscopic methods can be easily implemented in food mills and may be most useful for initial screening at early stages in the food production chain, enabling more costly methods to be used selectively for suspected specimens.
\end{abstract}

Key words: Fishmeal, Glycine max, meat meal, near infrared, principal component analysis, spectroscopy, soya meal.

\section{Introduction}

Quantitative determination of moisture, protein, fat (oil) and other minor chemical components accounts for the majority of applications of near infrared (NIR) spectroscopy in routine food and foodstuff analysis (Osborne et al., 1993; Aufrere et al., 1996; Fontaine et al., 2001; Cozzolino and Murray, 2004; Perez-Marín

Received 10 August 2008. Accepted 22 December 2008. Corresponding author: daniel.cozzolino@awri.com.au et al., 2004). However, the raw materials used in the manufacturing of compound feeds are variable both in composition and in nutritional quality due to multiple factors such as changes in temperature, infection with molds, fraud, or adulteration (Moya et al., 1994). The practical and economic repercussions of this variability are very important in the compound feed manufacturing industry, where a uniform product with both consistent composition and quality must be produced from inherently variable raw materials and by-products (Moya et al., 1994; Cozzolino and Murray, 2004). 
In an industrial setting, either qualitative or quantitative analytical control is essential in order to assess raw materials, products and byproducts and to optimize the manufacturing process itself (Blanco and Villaroya, 2002). In addition to chemical composition, important aspects of this assessment might relate to the process history of a product (e.g., fresh meat as opposed to frozen meat) or its geographic origin (e.g., Italian olive oil must be produced with olives grown only in Italy) (Downey, 1996; Arhurst and Dennis, 1996). Foods or raw ingredients that are most likely to be targets of adulteration include those that are of high value or that are subject to the effects of environmental conditions (e.g., rain and sun exposure) during their growth or harvesting (Murray et al., 2001; Gizzi et al., 2003). The practice of adulteration occurs for two main reasons: firstly, it can be profitable, and secondly, some adulterants can be easily mixed and are subsequently difficult to detect (Murray et al., 2001). In such cases, visual examination of the NIR spectra cannot discriminate between authentic and adulterated product (Downey, 1996). However, the application of multivariate data analysis techniques like principal component analysis (PCA) and discriminant analysis (e.g., discriminant partial least squares, linear discriminant analysis) might make it possible to unravel and interpret the optical properties of the sample, permitting classification without the use of chemical information (Downey, 1994 and 1996; Cordella et al., 2002).

The objective of this study was to explore the usefulness of near infrared reflectance (NIR) spectroscopy combined with chemometrics to discriminate between fishmeal, meat meal and soya meal samples in the feed mill industry.

\section{Materials and methods}

\section{Samples}

Seven samples of commercial fishmeal, ten samples of meat meal and fifteen samples of soya meal were collected from different industrial manufacturing plants. The samples were consid- ered to be authentic as defined by the suppliers. Samples were oven-dried at $100^{\circ} \mathrm{C}$ for $24 \mathrm{~h}$ and ground in a Wiley forage mill to pass a 1-mm screen (Arthur H. Thomas, Philadelphia, PA, USA) prior to NIR analysis.

\section{Near infrared reflectance (NIR) analysis}

Samples were analyzed in a NIRSystems 6500 scanning spectrophotometer (NIRSystems, Silver Spring, MD, USA) in reflectance mode (1100 $-2500 \mathrm{~nm}$ ), using the sample transport module in a $1 / 4$ rectangular cup, $60 \mathrm{~mm} \times 120 \mathrm{~mm}$, (NIRSystems part number 0IH - 0379, NIRSystems, MD, USA). Reflectance data were stored as $\log (1 / R)(R=$ reflectance $)$ at 2-nm intervals (700 data points). Each sample was scanned once (no repeated spectral measurements were made) and was not rotated during spectrum collection. Computer operation and spectral data collection were peformed using ISI version 3.1 software (InfraSoft International, Port Matilda, PA, USA).

\section{Multivariate data analysis}

Spectra were exported from the ISI software in ASCII format into the Unscrambler software (version 7.5, CAMO ASA, Norway) for chemometric analysis. Principal component analysis (PCA) of the spectra was performed using raw data and after pre-processing using the second derivative to reduce baseline variation and enhance the spectral features (Naes et al., 2002). Discrimination models were developed using the partial least squares discriminant (PLSDA) regression technique (Otto, 1999; Naes et al., 2002). In this technique, each sample in the calibration set is assigned a dummy variable as a reference value. The discrimination model is then developed by regression of the spectral data against the assigned reference value (dummy variable). The PLS-DA models were developed using a non-metric dummy variable (set to $1=$ fishmeal; 2 = meat meal and 3 = soya meal). Samples were classified according to meal type based on a cut-off value of 0.5. 
Full cross-validation (CV) (using the leave-oneout procedure) was used in development of the PCA and PLS-DA models (Naes et al., 2002). To evaluate the accuracy of the models thus generated and their ability to classify samples, we calculated the coefficient of regression (R) and the root mean square of the standard error in cross-validation.

\section{Results and discussion}

Figure 1 shows the mean NIR spectra of fishmeal, meat meal and soya meal after standard normal variate and de-trend (SNVD) transformation. The mean NIR spectra of fishmeal and meat meal samples were very similar. Absorption bands in the NIR region were observed at around $1200 \mathrm{~nm}, 1480 \mathrm{~nm}(\mathrm{O}-\mathrm{H}$ stretch second overtone, associated with water), $1700 \mathrm{~nm}$ (C-H first overtone, associated with lipids and oil), and between $1900 \mathrm{~nm}$ (O-H stretch second overtone) and $2300 \mathrm{~nm}(\mathrm{C}-\mathrm{H}$ combination tones, associated with water, amino acids and fatty acids) (Murray, 1986). The $2300 \mathrm{~nm}$ band acts as a reference point whose wavelength does not change across the spectra of a set of similar foods (Murray, 1986). Bands at $2058 \mathrm{~nm}$ and $2174 \mathrm{~nm}$ are related to the peptide absorption of the amide group. The mean NIR spectrum of the soya meal samples showed similar absorption bands to those described for fishmeal and meat meal. However, the absorption band at $1700 \mathrm{~nm}$ is not present in soya meal. The standard deviation of the NIR spectra (not shown) showed that wavelengths associated with water (variable moisture content) and oil are the most important in explaining the variation among the samples.

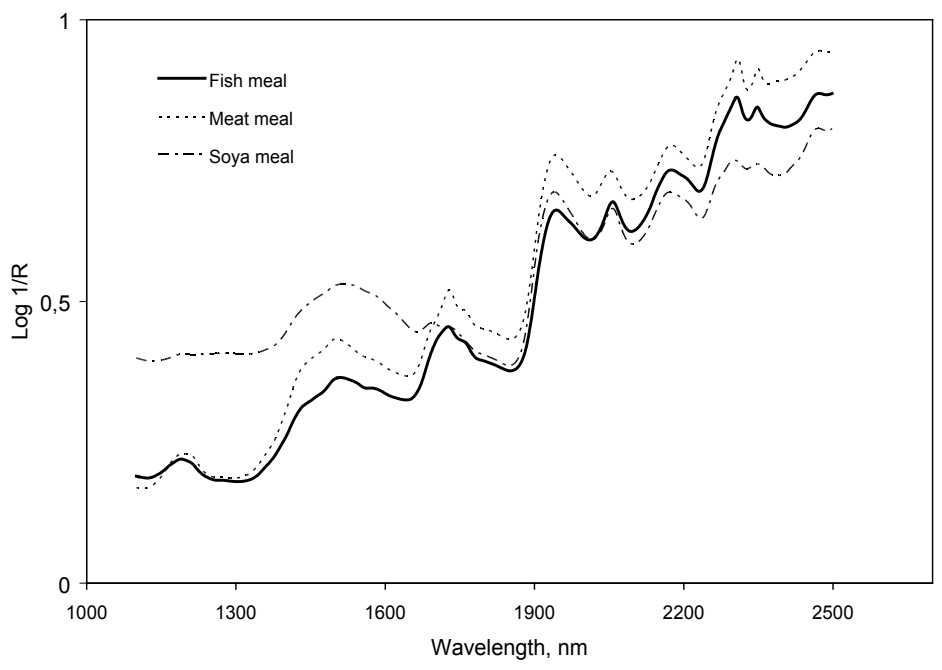

Figure 1. Mean near-infrared spectra of fish meal, meat meal and soya meal samples.

PCA was performed on the raw spectra to examine qualitative differences between the three types of meal samples analyzed. Figure 2 shows the score plot of the first two principal components (PCs) derived from the raw NIR spectra. A separation is found between groups of samples of different origin. The eigenvectors were analyzed in order to explain the differences in the PCA plot. Figure 3 shows the eigenvectors for the first three PCs. PC1 explains $86 \%$ of the total variance among the samples, and the largest eigenvector magnitudes were found at around $1600 \mathrm{~nm}$ (C-H first overtone), at 1900 $\mathrm{nm}(\mathrm{O}-\mathrm{H}$ stretch first overtone, associated with water content), and between 2100 and $2300 \mathrm{~nm}$ (C-H combination tones, associated with either unsaturated fatty acids or aromatic amino acids) (Murray, 1986; Miller, 2001). PC2 explains 
$12 \%$ of the variation, and the largest eigenvector magnitudes were found at around $1450 \mathrm{~nm}$ and $1920 \mathrm{~nm}$, both related to O-H overtones associated with water content (Murray, 1986).

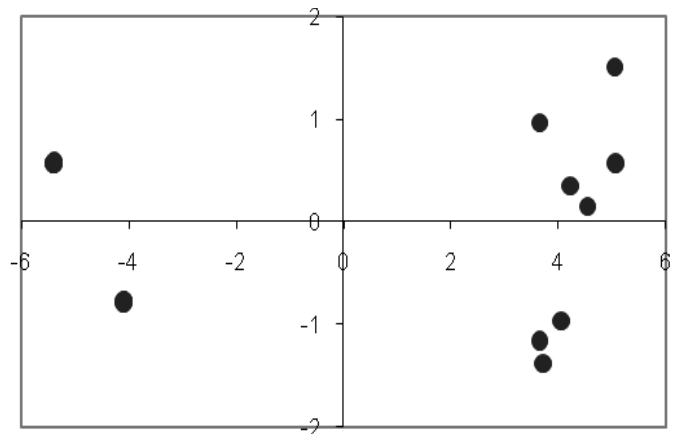

Figure 2. Score plot of the first two principal components of the NIR spectra of fishmeal, meat meal and soya meal samples.
PCA analysis (not shown). PLS-DA correctly classified $85.7 \%$ of the fishmeal samples and $100 \%$ of the meat meal and soya meal samples. The fishmeal samples that were incorrectly classified had very low crude protein content, similar to the meat meal samples. The ability of the NIR-based model to classify the meal samples is based on the vibrational responses of chemical bonds in the near infrared region $(\mathrm{O}-\mathrm{H}, \mathrm{N}-\mathrm{H}$ and $\mathrm{C}-\mathrm{H}$ ). It is probable that greater variability between the sample types in those chemical entities (e.g., protein or oil content) that respond in these regions of the spectrum leads to better accuracy of the model. This explains the strong separation obtained between samples of animal origin (fishmeal and meat meal) versus samples of plant origin. Our results also suggest that other characteristics (e.g., amino acids and fatty acids) may explain the discrimination among samples.

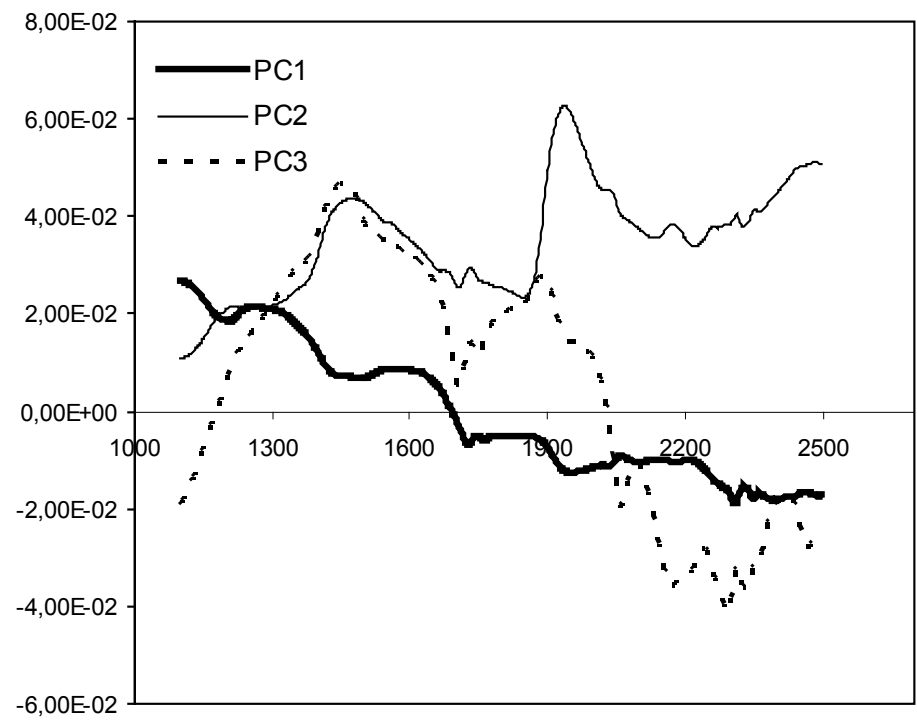

Figure 3. Eigenvectors of the first three principal components of the NIR spectra of fishmeal, meat meal and soya meal samples.

Table 1 shows the calibration statistics and classification results from PLS-DA regression models developed using the raw spectra. These PLSDA models accounted for $96 \%$ and $92 \%$ of the variability in calibration and validation, respectively. PLS loadings of the calibration models for discrimination between sample types were similar to the eigenvectors described for the
As suggested by other authors, NIR spectroscopy might be used as a first line of defense against accidental contamination (e.g., cross-contamination) and fraudulent practices or for screening of the raw material (Murray et al., 2001; Gizzi et al., 2003). NIR spectroscopic methods can be easily implemented in food mills. These methods may be most useful for initial screening at early stag- 
Table 1. Discriminant partial least squares calibration statistics, validation statistics and classification results of fishmeal, meat meal and soya meal samples using near infrared reflectance spectroscopy.

\begin{tabular}{lccccc}
\hline & $\mathrm{R}^{1}$ & $\mathrm{RMSECV}^{1}$ & $\mathrm{PLS} \mathrm{t}^{1}$ & Slope $^{1}$ \\
\hline Calibration $(\mathrm{n}=16)$ & 0.96 & 0.13 & 6 & \\
Validation $(\mathrm{n}=16)$ & 0.92 & 0.20 & & Correct classification, \% & 0.88 \\
\cline { 3 - 5 } & & & $\begin{array}{c}\mathrm{FM}^{1} \\
(\mathrm{n}=7)\end{array}$ & $\begin{array}{c}\mathrm{MM}^{1} \\
(\mathrm{n}=10)\end{array}$ & $\begin{array}{c}\mathrm{SM}^{1} \\
(\mathrm{n}=15)\end{array}$ \\
\cline { 2 - 5 } Classification & FM & 85.7 & 14.3 & 0.0 \\
& MM & 0.0 & 100.0 & 0.0 \\
& $\mathrm{SM}$ & 0.0 & 0.0 & 100.0 \\
\hline
\end{tabular}

${ }^{1} \mathrm{FM}$ : fishmeal; MM: meat meal; SM: soya meal; R: coefficient of regression; RMSECV: root mean square of the standard error in crossvalidation; PLS t: number of terms used to develop the calibration models; n: number of samples.

es in the food production chain, enabling more costly methods to be used selectively for further examination of doubtful specimens. To be able to control and optimize the processing of fishmeal, it is important to measure and analyze the chemical composition of the raw material. Additional qualitative analysis may be possible using NIR spectroscopy and should be incorporated into routine NIR analyses in the feed industry.

Although the work reported here constitutes a preliminary study and requires further develop- ment, we have shown that more than $85 \%$ of the samples were classified correctly into three groups according to sample type by NIR spectroscopy. These results suggest that feed mills can use NIR spectroscopy for the identification and authentication of the products that they produce.

\section{Acknowledgments}

This work was supported by the National Institute for Agricultural Research (INIA), Uruguay.

\section{Resumen}

D. Cozzolino, E. Restaino, A. La Manna, E. Fernandez y A. Fassio. 2009. Uso de la espectrofotometría de reflectancia en el infrarrojo cercano (NIR) y la quimiometría para discriminar entre muestras de harinas de pescado, carne y soja. Cien. Inv. Agr. 36(2):209214. El objetivo de este trabajo fue investigar el uso de la espectrofotometría de reflectancia en el infrarrojo cercano (NIR) en combinación con la quimiometría para discriminar muestras de harinas de pescado, carne y soja. Muestras provenientes de molinos racioneros comerciales fueron leídas en un equipo monocromador NIRS (NIRSystems, Silver Spring, USA) en el rango de longitudes de onda de 400 a $2500 \mathrm{~nm}$, en reflectancia. Análisis de componentes principales (APC) y de discriminantes utilizando la técnica de los cuadrados mínimos parciales (PLS-DA) fueron usados para clasificar las muestras de acuerdo a su origen. El método de la validación cruzada fue utilizado para validar los modelos. El $85,7 \%$ de las muestras de harina de pescado y el $100 \%$ de las muestras de carne y soja fueron correctamente clasificados usando el método PLS-DA. Los resultados obtenidos en este estudio demuestran el potencial uso de la reflectancia en el infrarrojo cercano combinada con la quimiometría como un método rápido y de bajo costo para clasificar muestras de harina de pescado, carne y soja.

Palabras clave: Análisis de componentes principales, espectrofotometría de reflectancia, Glycine max, infrarrojo cercano, harina de pescado, harina de soja. 


\section{References}

Arhurst, P.R., and M.J. Dennis. 1996. Food Authentication. Chapmann-Hall, London, UK. 315 pp.

Aufrere, J., D. Graviou, C. Demarquilly, J.M. Perez, and J. Andrieu. 1996. Near infrared reflectance spectroscopy to predict energy value of compound feeds for swine and ruminants. Animal Feed Science and Technology 62:77-90.

Blanco, M., and I. Villaroya. 2002. NIR spectroscopy: a rapid-response analytical tool. Trends in Analytical Chemist 21:240-250.

Cordella, C., I. Moussa, A-C. Martel, N. Sbirrazzuoli, and L. Lizzani-Cuvelier. 2002. Recent developments in food characterisation and adulteration detection: technique-oriented perspectives. Journal of Agriculture and Food Chemistry 50:1751-1764.

Cozzolino, D., and I. Murray. 2004. Analysis of animal by-products. Pages 647-662. In: C.A. Roberts, J. Workman Jr., and J.B. Reeves III (eds.). Near Infrared Spectroscopy in Agriculture. Agronomy Monographs 44, American Society of Agronomy, Crop Science Society of America, Soil Science Society of America. Wisconsin, USA.

Downey, G. 1994. Qualitative analysis in the Near Infrared region. The Analyst 119:2367-2375.

Downey, G. 1996. Authentication of food and food ingredients by near infrared spectroscopy. Journal of Near Infrared Spectroscopy 4:47-61.

Fontaine, J., J. Horr, and B. Schirmer. 2001. Near infrared reflectance spectroscopy enables the fast and accurate prediction of the essential amino acids content in soy, rapeseed meal, sunflower meal, peas, fishmeal, meat meal products and poultry meal. Journal of Agriculture and Food Chemistry 49:57-66.

Gizzi, G., L.W.D. van Raamsdonk, V. Baeten, I. Murray, G. Berben, G. Brambilla, and C. von Holst. 2003. An overview of test for animal tissues in feeds applied in response to public health concerns regarding bovine spongiform encephal- opathy. Revue Scientifique et Technique (International Office of Epizootics) 22:311-331.

Miller, Ch. E. 2001. Chemical principles of near infrared technology. Pages 19-39. In: P.C. Williams and K.H. Norris. (eds.). Near infrared technology in the agricultural and food industries. Second Edition. American Association of Cereal Chemist, Minnesota, USA.

Moya, L., A. Garrido, J.E. Guerrero, J. Lizaso, and A. Gomez. 1994. Quality control of raw materials in the feed compound industry. Pages 111116. In: G.D. Batten, P.C. Flinn, L.A. Welsh, and A.B. Blakeney (eds.). Leaping ahead with near infrared spectroscopy. Royal Australian Chemical Institute, Melbourne, Australia.

Murray, I. 1986. The NIR spectra of homologous series of organic compounds. Pages 13-28. In: J. Hollo, K.J. Kaffka, and J.L. Gonczy (eds.). Proceedings of the International NIR/NIT Conference. Akademiai Kiado, Budapest, Hungary.

Murray, I., L. Aucott, and I.H. Pike. 2001. Use of discriminant analysis on visible and near infrared reflectance spectra to detect adulteration of fishmeal with meat and bone meal. Journal of Near Infrared Spectroscopy 9:297-311.

Naes, T., T. Isaksson, T. Fearn, and T. Davies. 2002. A User-friendly guide to multivariate calibration and classification. NIR Publications, Chichester, UK. 420 pp.

Osborne, B.G., T. Fearn, and P.H. Hindle. 1993. Practical NIR Spectroscopy with applications in food and beverage analysis. Second Edition. Longman Scientific and Technical, Harlow, Essex, UK. 227 pp.

Otto, M. 1999. Chemometrics. Statistics and computer application in analytical chemistry. WileyVCH Verlag, Weinheim, Germany. 314 pp.

Pérez-Marín, D.C., A. Garrido-Varo, J.E. GuerreroGinel, and A. Gómez-Cabrera. 2004. Near infrared reflectance spectroscopy (NIRS) for the mandatory labelling of compound feedingstuffs: chemical composition and open declaration. Animal Feed Science and Technology 116:333-349. 